\title{
The Effect of Suspension Workout on Agility and Forces Performance in Elite Basketball Players
}

\author{
Özgür Nalbant ${ }^{1}$, Ahmet Metin Kınık ${ }^{1}$ \\ ${ }^{1}$ Alanya Alaaddin Keykubat University, Sports Science Faculty, Turkey \\ Correspondence: Assist. Prof. Dr. Özgür Nalbant, Alanya Alaaddin Keykubat University, Sports Science Faculty, \\ Turkey.
}

Received: March 7, 2018

Accepted: April 28, $2018 \quad$ Online Published: May 3, 2018

doi:10.11114/jets.v6i6.3257

URL: https://doi.org/10.11114/jets.v6i6.3257

\begin{abstract}
The purpose of this study is to determine the effect of suspension training on agility and strength performance in elite male basketball players. The study was carried out on Demir İnşaat Büyükçekmece male U-21 basketball players who are the members of one of the U-21 teams of the Turkish Basketball Federation. 20 volunteer basketball players with age of $18,3 \pm 0,3$ years; the training ages of $6.5 \pm 1.3$ years; the lengths of $189.45 \pm 7.3 \mathrm{~cm}$; weights of $82.9 \pm 7.8 \mathrm{~kg}$ and body mass index of $23 \pm 1.3$ were participated in the study. This group was used as both control and experimental group. Following their first tests, the group participating in the study continued their regular routine training for 6 weeks. After six weeks, the second measurements were taken. These measurements were also accepted as the last measurement of the group which was considered as the control group, while those measurements were accepted as the first measurement of the test group. Afterwards, suspension training (TRX) was performed twice a week right along with basketball training for 6 weeks. At the end of six weeks, the tests were repeated and the level of development of the test group was determined. In the study group, right and left hip flexility test, sitting down flexibility test, standing long jump test, vertical jump test, back and leg strength, T-test and 20-meter sprint tests were performed. The obtained data were analyzed in the SPSS program and descriptive statistics, Anova Test and Bonferroni correction were performed. As a result, there was a significant difference in hip flexion, jump, strength and agility tests $(p<0.05)$. According to these results, suspension TRX training was found to have positive effects on elite male basketball players.
\end{abstract}

Keywords: basketball, suspension training, trx, agility, strength

\section{Introduction}

Basketball is a universal sport where information are consumed intensely and in our age, called information age, its popularity is rapidly growing compared to other sports branches. In this sport, information consumption is also leading person to forgetting and monotony. The monotony of basketball-specific work and the inability to reveal new work are getting this ever renewing team sport back.

In today's basketball, there seems to be an increase in physical demands as well as changes in rules and game strategies. It is necessary to be faster in the basketball than the opponents, to jump higher and to increase the rate of successful shooting. Beside this, it is also necessary to increase the physical fitness parameters such as strength, endurance and balance specific to basketball (Schelling 2013, Abdelkrim 2007, Cormery, 2008).

In addition to traditional training methods, there are also commonly used training methods in today's training programs and fitness facilities. These are done on different platforms such as bosu ball, pilates ball and thera-band (Anderson 2004, Marshall 2006, Santana 2007) or with materials that are complement to open kinetic chain exercises using free weights. More recently, the suspension training system Pro Suspension Training System (TRX) has been added to this group of materials (Gaetz 2004, Holtzmann 2004, Marshall 2006).

The basis of the exercises made with their own body weight is based on the core training technique. Core training can be performed with only body weight without the requirement of any tools and it also can offer rich exercise options with the use of different materials. The use of materials such as TRX, bosu ball, pilates ball, elastic bands, together with core exercises, allows the core training to be applied on both fixed and unstable surfaces. Core training is designed as flexibility trainings, training done with own body weight (Stable floor movements), balance trainings (TRX, pilates and bosu), thera-band (rubber band). We can easily say that TRX studies are among the training priorities in basketball because of the importance of balance (Savaş 2013). 
TRX has emerged as America's Total Resistance Exercise in the early 20th century by Randy Henrik. In suspension training, the person's own body weight is used at first place. All that is required is the correct suspension point and the different regions can be worked in the desired position. It is not an easy task to make the supporting muscle groups work as the main muscle group is working. However, this is possible with TRX trainings. In these studies, the difficulty is to resist the gravity. The muscle groups, involved in the training, use the body as a leverage system. During the trainings, movements according to the position of the body are in the form of pulling or pushing in all three planes. TRX trainings are suitable for amateur or professional people who want to improve their physical capacity and functionality (Pastucha 2012).

TRX is a strength exercise that applies only to resistance to own body weight without any additional weight. Especially, it can be applied for beginners to strength studies or as recommended training style for athletes (Soydan 2006). The suspension training intensity can be modified by changing the body positions and angles according to the suspension point (Ronai 2016). When we research the literature, we have studies mostly dealt with muscle activation and biomechanics of single movement while there are limited studies dealing with the effects of suspension training (Calatayud 2013, Snarr 2013, Dudgeon 2015). However, no trainings have been mentioned, in addition to the training methods. This study assesses the effects of TRX training on elite male basketball players over six weeks of agility and strength performance.

\section{Materials and Methods}

The study was conducted and limited by 20 volunteer athletes from Demir İnşaat Büyükçekmece male U-21 team players who play in the Turkish Basketball Federation U-21 League. The average age of participants was $18.3 \pm 0.3$ years; average of training ages was $6,5 \pm 1,3$ years; average of the lengths was $189.45 \pm 7.3 \mathrm{~cm}$; average of the weights was $82,9 \pm 7,8 \mathrm{~kg}$. and average of body mass index was $23 \pm 1.3$.

As criteria for participation in the study; The volunteers must be basketball players, be regularly trained, have no health problems influencing the study, and be volunteers. For a criterion for getting out of the study; they should give up trainings, not to participate in at least three trainings, be injured, have a health problem that would affect the studies, and quit by their own will.

Participants were informed with a weekly preliminary training on the planned schedule and a consent form was signed. A single group for the study was used as both control and experimental group. This is because it is impossible to find a different group on the same criteria that can be taken into account. After taking the first tests of the group participating in the study, they continued their basketball trainings for 6 weeks. After six weeks, the second measurements were taken. These measurements were also the last measurement of the study group, which was also considered as the control group, and the first measurement of the test group. Afterwards, TRX training was performed twice a week in addition to basketball trainings for 6 weeks. The Pro Suspension Training System (TRX) kit was used in the studies. At the end of six weeks, the tests were repeated and the level of development of the test group was determined. Performance tests were spreaded over 2 days. On the first day, after 5 minutes of free running and after 4 minutes of static stretching, right (GANIOR) and left (GANIOL) hip flexility test, sitting elongation flexibility test (OTER), standing long jump test (DUA), vertical jump test (DIS), back force (SIRTK) and leg strength (BACAKK) measurements were taken and the next day, after five minutes of free running, static stretching was performed for 4 minutes. Afterwards, T-test (TDRIL) and 20-meter sprint (YM) tests were performed to basketball players. The obtained data were analyzed in the SPSS program and descriptive statistics, Anova Test and Bonferroni correction were performed.

In the basketball player's work schedule, they made Squat, Chest Press, Single Leg Squat, Push Up, Stepping Side Lunge, Deltoid Fly, Suspended Lunge, Anatomic Push Up, Hamsting Crull Hips and High Back Row. Participants made these movements 10 repeats -2 sets in the first three weeks, 12 repeats - 3 sets in the last three weeks. 1 minute rest was given between sets. The pace of the applications was determined by the metronome to be 30 RPM.

\section{Results}

In the study it was found that there was a significant difference in weight and body mass index between the final measurements and the first two measurements of participants (Table 1).

Table 1. Descriptive Statistics of Participants

\begin{tabular}{lllc}
\hline & Min. & Max. & Mean \pm Std.dev. \\
\hline Age (year) & 17,00 & 19,00 & $18,30 \pm 0,8$ \\
Height (cm) & 178,00 & 203,00 & $189,45 \pm 7,3$ \\
Weight (kg) & 70,90 & 98,40 & $82,92 \pm 7,8$ \\
BMI (kg/m ${ }^{2}$ ) & 21,40 & 27,50 & $23,06 \pm 1,3$ \\
\hline
\end{tabular}

There was no significant difference between GANIOR1 and GANIOR2 according to the findings of elasticity 
measurements, but there was a significant difference between GANIOR2 - GANIOR3 and GANIOR1 - GANIOR3 (Table 2). There was also a significant difference between GANIOL1-GANIOL2, GANIOL2-GANIOL3 and GANIOL1-GANIOL3 (Table 3). In addition, there was also a significant difference between OTER2 - OTER3 and OTER1 - OTER3 (Table 4).

Table 2. GANIO R (Pre-test, Week 6, Week 12 Measurement averages)

\begin{tabular}{lllll}
\hline Measurement & Mean & Std.Deviation & $\mathbf{N}$ & $\mathbf{p}$ \\
\hline GANIO R1 & 76,500 & 7,272 & 20 &, 000 \\
GANIO R2 & 75,850 & 6,706 & 20 & \\
GANIO R3 & 88,900 & 8,302 & 20 & \\
\hline$(\mathrm{p}<0.05)$ & & & &
\end{tabular}

Table 3. GANIO L (Pre-test, Week 6, Week 12 Measurement averages)

\begin{tabular}{lllll}
\hline Measurement & Mean & Std.Deviation & N & p \\
\hline GANIO L1 & 76,600 & 8,857 & 20 &, 000 \\
GANIO L2 & 73,750 & 8,071 & 20 & \\
GANIO L3 & 88,800 & 8,101 & 20 & \\
\hline$(\mathrm{p}<0.05)$ & & & &
\end{tabular}

Table 4. OTER (Pre-test, Week 6, Week 12 Measurement averages)

\begin{tabular}{lllll}
\hline Measurement & Mean & Std.Deviation & $\mathbf{N}$ & $\mathbf{p}$ \\
\hline OTER 1 & 26,200 & 7,977 & 20 &, 000 \\
OTER2 & 25,075 & 7,790 & 20 & \\
OTER3 & 29,700 & 6,325 & 20 & \\
\hline$(\mathrm{p}<0.05)$ & & & &
\end{tabular}

There was a significant difference between DUA2-DUA3 and DUA1-DUA3 (Table 5) when there was no significant difference between DUA1 and DUA2 according to the findings obtained by strength measurements in the study. There was also a significant difference between DIS2-DIS3 and DIS 1-DIS3 (Table 6).

Table 5. DUA (Pre-test, Week 6, Week 12 Measurement averages)

\begin{tabular}{lllll}
\hline Measurement & Mean & Std.Deviation & N & p \\
\hline DUA1 & 217,0500 & 17,48225 & 20 &, 000 \\
DUA2 & 214,8500 & 15,98116 & 20 & \\
DUA3 & 230,0500 & 13,18881 & 20 & \\
\hline$(\mathrm{p}<0.05)$ & & & &
\end{tabular}

Table 6. DIS (Pre-test, Week 6, Week 12 Measurement averages)

\begin{tabular}{lllll}
\hline Measurement & Mean & Std.Deviation & $\mathbf{N}$ & $\mathbf{p}$ \\
\hline DIS1 & 52,1750 & 7,68675 & 20 &, 000 \\
DIS2 & 51,4500 & 7,53570 & 20 & \\
DIS3 & 56,3000 & 6,40805 & 20 & \\
\hline$(\mathrm{p}<0.05)$ & & & &
\end{tabular}

There was a significant difference between TDRIL2-T DRIL3 and TDRIL1-TDRIL3 (Table 6) when there was no significant difference between TDRIL1 and TDRIL2 in the skill test. A significant difference was also observed between YM2-YM3 and YM1-YM3 (Table 8).

Table 7. T DRIL (Pre-test, Week 6, Week 12 Measurement averages)

\begin{tabular}{lllll}
\hline Measurement & Mean & Std.Deviation & N & $\mathbf{p}$ \\
\hline T DRIL1 & 9,9578 &, 44370 & 20 &, 000 \\
T DRIL2 & 9,9786 &, 35902 & 20 & \\
T DRIL3 & 9,6108 &, 35035 & 20 & \\
\hline$(\mathrm{p}<0.05)$ & & & &
\end{tabular}

Table 8. $Y M$ (Pre-test, Week 6, Week 12 Measurement averages)

\begin{tabular}{lllll}
\hline Measurement & Mean & Std.Deviation & N & p \\
\hline YM1 & 3,4159 &, 17184 & 19 &, 000 \\
YM2 & 3,4178 &, 16292 & 19 & \\
YM3 & 3,1907 &, 15912 & 19 & \\
\hline$(\mathrm{p}<0.05)$ & & & &
\end{tabular}


There was a significant difference between SIRT2-SIRT3, SIRT1-SIRT3 and BACAKK2-BACAKK3 when there was no significant difference between SIRTK1-SIRTK2 and BACAKK1-BACAKK2 (Table 9, Table 10).

Table 9. SIRTK (Pre-test, Week 6, Week 12 Measurement averages)

\begin{tabular}{lllll}
\hline Measurement & Mean & Std.Deviation & N & p \\
\hline SIRTK1 & 118,9750 & 17,66685 & 20 &, 000 \\
SIRTK2 & 119,5750 & 17,35335 & 20 & \\
SIRTK3 & 133,3750 & 18,68004 & 20 & \\
\hline$(\mathrm{p}<0.05)$ & & & &
\end{tabular}

Table 10. BACAKK (Pre-test, Week 6, Week 12 Measurement averages)

\begin{tabular}{lllll}
\hline Measurement & Mean & Std.Deviation & N & p \\
\hline BACAKK1 & 132,9000 & 35,71952 & 20 &, 002 \\
BACAKK2 & 126,9750 & 24,39180 & 20 & \\
BACAKK3 & 143,6950 & 23,12250 & 20 & \\
\hline$(\mathrm{p}<0.05)$ & & &
\end{tabular}

It is observed that the post-training effects of the TRX studies applied to the experimental group in the study made significant results.

\section{Discussion and Conclusion}

In this study, the effect of the TRX suspension training system on the strength and quickness parameters of six-week elite young male basketball players was examined.

The changes and differences in weight and body mass index as a result of the measurements can be explained as the increase of energy consumption at the beginning of TRX applications after the second measurement. Because the long duration submaximal exercise done without break activates the body's fat burning system (Ergen E., 2002). Similar findings have also been observed in the study conducted in 2015 by Kyung-Hun Yu and his colleagues on monopalet swimmers.

Significant changes in the right and left active hip flexion (GANIO R and GANIO L) and flexibility (OTER) in the study showed that, since the movements in the suspension training are done in the large angles, it also improved joint movement spacing and enhanced flexibility. In other words, the functionality of the joint has increased. When the joint movement is excessive, tendons have more angular effect (Fox, Bowers, Foss; 2012 ). It can be considered that the TRX studies carried out during the study increased the range of motion of the joint with angular eccentric contraction and thus the flexibility increased.

A significant difference in standing long jump (SLJ) and vertical jump (VJ) after TRX training is parallel to the strength development of the core, back and leg muscles that contribute to jump performance. It is also an important factor in sports that require speed and explosive strength (Shaver, 1970; Muratl, 2011). Suspension movements increase balance with strenght, resulting in more muscle innerving, thus leading to significancy in positive direction in 20 meters speed (YM). Similar results have been achieved in our study in accordance with the studies performed by Cengiz Taşkın (2016) on female footballers, by Gökhan Doğan (2016) on footballers and by Merve Şenol (2015) on swimming.

It can be said that the study has significant effects on the agility performance of the pelvic and lower limb movements of the right and left legs, especially for changing the direction. Because TRX studies have a positive effect on abdominal muscles and pelvic bone (Bryne, 2014). Mario Tomljanović and his colleagues (2011) also found that the agility performance was positively affected in their study.

TRX studies conducted with self-weighted body weight, with isotonic contractions in suspension training in which balance come into prominence, can be considered to have significant results in back and leg strength measurements. This is because the suspension training is often used as a method that is often used in the treatment of many trunk muscles that hold the spine (electro spina) and hip stable, such as the core exercises.All of these muscles work together to keep the body in balance during movement. In many movements, isometric or isotonic contraction of these muscles can be strengthened by using different training methods with similar types of contractions (Aşş1, 2011).

As a result, evolving technology has led to the development of many new training equipment to enforce people's borders and improve physical performance. The equipment we used in our study is the suspension training system used today. It has been determined that this system has a positive impact on agility and strength performance in suspension training for basketball players over a six week period. According to this result, it can be said that suspension training can be used to improve the agility and strength performance of basketball players. 


\section{Recommendations}

1. More chronic studies of suspension training should be done.

2. Adaptive training should be done before starting suspension training and suspension training should be started afterwards.

3. When preparing the suspension training programs, the correct form of movement for the body should be selected and implemented.

4. The movements and difficulty ratings to choose in suspension training should be specific to the sport.

\section{References}

Abdelkrim, N., El Fazaa, S., \& El Ati, J. (2007). Time-motion analysis and physiological data of elite under-19-year-old basketball players during competition. The British Journal of Sports Medicine, 41, 69-75. https://doi.org/10.1136/bjsm.2006.032318

Anderson, K. G., \& Behm, D. G. (2004). Maintenance of EMG activity and loss of force output with instability. Journal Strength and Conditioning Research, 18, 637-640.

Aşçı, A. (2011). Core training practice in team and individual sports, 4th Training Science Congress Abstract Book, Ankara, Turkey.

Byrne, J. M., Bishop, N. S., Caines, A. M., Feaver, A. M., \& Pearcey, G. E. (2014). Effect of a suspension training system on muscle activation during the performance of a front plank exercise, Journal Strength and Conditioning Research, 28(11), 3049-3055. https://doi.org/10.1519/JSC.0000000000000510

Cormery, B., Marcil, M., \& Bouvard, M. (2008). Rule change incidence on physiological characteristics of elite basketball players: A 10-year-period investigation. The British Journal of Sports Medicine, 42, 25-30. https://doi.org/10.1136/bjsm.2006.033316

Dalibor, P., Radka, F., Marcela, B., Eliska, S., \& Vit, C. (2013). Clinical anatomy aspects of functional 3D training case study; Biomed Pap Med Fac Univ Palacky Olomouc Czech Repub. Mar; 156(1), 63-69.

Dogan, G. A., Mendei, B., Akçan, F., \& Tepe, A. (2016), Effects of eight weeks of core training on football players on some physical and physiological parameters, Journal of Physical Education and Sports Sciences, 10(1), Niğde.

Ergen, E. (2002), Exercise Physiology, Nobel Academic Publishing, Ankara, 3.1.

Flood, C. (2016). Effect of core training program on physical functional performance in female soccer players", International Education Studies, 9.

Fox, E. L., Bowers, R. W., \& Foss, M. L. (2012). Physiological Foundations of Physical Education and Sports, Sport Publishing House, Ankara, Turkey.

Gaetz, M., Norwood, J., \& Anderson, G. (2004). EMG activity of trunk stabilizers during stable / unstable bench press. Canadian Journal of Applied Physiology, 29, 48.

Holtzmann, M., Gaetz, M., \&d Anderson, G. EMG activity of trunk stabilizers during stable and unstable push-ups. Canadian Journal of Applied Physiology, 29, 35.

Joaquin, C. S. B., Juan, C. C., Fernando, F. M., Michael, E. R., David, G. B., \& Lars, L. A. (2013). Muscle activation during push-ups with different suspension training systems. Journal of Sports Science and Medicine, $13(3), 3.1$.

Kyung-Hun, Y., Min-Hwa, S., Shin-Woo, K., \& Yun, A. S. (2015). Effect of combined resistance training with TRX on physical fitness and competition times in Fin swimmers. International Journal of Sport Studies, 5(5), 508-515.

Marshall, P. W., \& Murphy, B. A. (2006). Increased deltoid and abdominal muscle activity during Swiss ball bench press. The Journal of Strength and Condition Research, 20, 745-750.

Marshall, P., \& Murphy, B. (2006). Changes in muscle activity and perceived exertion during exercises on a Swiss ball. Applied Physiology Nutrition Metabolism, 31, 376-383. https://doi.org/10.1139/h06-006

Muratlı, S., Kalyoncu, O., \& Sahin, G. (2011). Training and Competition, Kalyoncu Sports Consulting Ltd. Şti, Istanbul, 3.1 .

Peter, R., \& Eric, S. (2016). The Suspension Inverted Row, National Strength and Conditioning Association, $38(4), 106$. https://doi.org/10.1519/SSC.0000000000000226

Ronald, L., \& Snarr, M. R. E. (2013). Electromyographic comparison of traditional and suspension push-ups. Journal of Human Kinetics, 39, 3.1. 
Santana, J. C., Vera-Garcia, F. J., \& McGill, S. M. (2007). A kinetic and electromyographic comparison of the standing cable press and bench press. The Journal of Strength and Condition Research, 21, 1217-1277.

Şenol, M. (2015) . The Effect of Functional Exercise Band and Body Weight on the Swimming Performance of Force Trainings. 6.Congress of Training Science Presentation Ankara, Turkey.

Seyfi, S. (2013). Performance of Core Stabilization and Tera band applications in Basketball. 5. Training information congress abstract book Hacettepe, p: 33.

Shaver, G. L. (1970). Effect of Training on Relative Muscular Endurance In Ipsilateral and Contralateral Arms, Medicine \& Sceince In Sports, 2(3), 165-171, New York. https://doi.org/10.1249/00005768-197023000-00012

Soydan, S. (2006) Age Group Made for Female Athletes Classical and Body Weight 8 Weekly Strength Training is 200m.Influence of Transition Levels on Free Floating. Master Thesis. Kocaeli University Health Sciences Institute.

Taşkın, C. (2016). Effect of core training program on physical functional performance in female soccer players, International Education Studies, 9.

Tomljanovic, M. A., Spasic, M., Gabrilo, G., Uljevic, O., \& Foretic, N. (2011). Effect of five weeks of functional vs. Traditional resistance training on anthropometric and motor performance variables, Faculty of Kinesiology, University of Split, Croatia, 43(2), 145-154.

Wesley, D., David, D. T., Judith, M. H., \& Elizabeth, P. K. (2015). Physiologic and Metabolic Effects of a Suspension Training Workout, International Journal of Sports Science, 5(2), 65-72.

Xavi, S., \& Lorena, T. R. (2013). Conditioning for Basketball: Quality and Quantity of Training, Strength and Conditioning Journal, 35(6), 89-94. https://doi.org/10.1519/SSC.0000000000000018

\section{Copyrights}

Copyright for this article is retained by the author(s), with first publication rights granted to the journal.

This is an open-access article distributed under the terms and conditions of the Creative Commons Attribution license which permits unrestricted use, distribution, and reproduction in any medium, provided the original work is properly cited. 